\title{
Habilidade Cognitiva Espacial: uma medida com eletroencefalografia
}

Marilda Spindola Chiaramonte

Orientador: Milton Antônio Zaro

Coorientador: Maria Isabel Timm

Data da defesa: 9 de abril 2010

A presente tese apresenta uma contribuição à área da pesquisa educacional, para auxiliar na identificação de perfis cognitivos, utilizando o referencial teórico das Ciências Cognitivas e a instrumentação das Neurociências. O projeto elaborado para atender os objetivos desta tese compreendeu o desenvolvimento de metodologia experimental, apoiada pela técnica estatística de Projetos de Experimentos, juntamente com instrumentos neurocientíficos (uso de eletroencefalografia com técnica ERP - Event Related Potential), para a observação, quantificação e interpretação de evidências neuronais - sinais de eletroencefalografia - relacionadas ao processo cognitivo humano. Buscou, em particular, evidências relacionadas às diferentes demandas de energia despendida na realização de atividades espaciais (identificação, percepção ou atenção espacial de objetos virtuais), com base em instrumentos teóricos e tecnológicos das Neurociências, das Ciências Cognitivas e da Psicologia Cognitiva, para uso na área da pesquisa educacional, visando contribuir para identificação de diferentes perfis de estudantes em diferentes áreas do conhecimento. Na investigação experimental, o objetivo foi buscar indicadores (quantificação de energia alocada em atividade cerebral, medida de tempo de resposta ao estímulo, maior magnitude na faixa de freqüência do ritmo elétrico cerebral, evocados no experimento) dos sinais cerebrais que estejam sincronizados com o exercício proposto e que possam subsidiar a hipótese de que há diferenças significativas entre estudantes de áreas científicas e tecnológicas e estudantes de áreas humanas e sociais, no quesito habilidades espaciais. A proposta contextualiza e fundamenta experimentos com um grupo de alunos voluntários dos cursos de graduação, selecionados para a pesquisa, classificados por idade e sexo e avaliados e selecionados por diagnóstico psicológico indicativo da provável área de aptidão/habilidade cognitiva. O desenvolvimento da proposta investigativa, que visou atender os objetivos relacionados e pertinentes ao processo, foi possível devido a esforços de pesquisadores e cientistas das diferentes áreas de conhecimento, que colaboraram na modelagem do experimento realizado no Laboratório de Biosinais da Universidade de Caxias do Sul, no Campus Universitário da Região dos Vinhedos, junto ao Curso de Engenharia Elétrica. Como parte do processo metodológico experimental está compreendido o desenvolvimento do instrumento de medição: equipamento de eletroencefalografia (EEG) utilizando o sistema de aquisição e conversão de sinal analógico-digital da National Instruments e também, o equipamento conhecido como Gaiola de Faraday, que serviu para a realização das coletas de sinais elétricos cerebrais de baixa freqüência e amplitude, minimizando a presença de ruídos eletromagnéticos interferentes significativamente no sinal coletado. Os dados (sinais elétricos cerebrais) coletados durante o experimento que evocou raciocínio lógico espacial dos participantes foram modelados matematicamente por Fourier e interpretados por análise estatística - UNIVARIATE (análise de variância) e comparados aos resultados obtidos pelos instrumentos de apoio utilizados como forma de validar o processo investigativo: questionário verbal ao final do experimento e teste psicológico - subteste BPR5 - RE. Todos os dados coletados também foram armazenados com o propósito de permitir futura realização de outras simulações, com diferentes métodos de acesso aos conteúdos. Entende-se que os resultados obtidos nesse experimento possam colaborar com a Informática aplicada à Educação no planejamento, desenvolvimento e uso de objetos virtuais em ambientes destinados a mediar à aprendizagem, de acordo com necessidades específicas de cada público-alvo. Nesse sentido, os resultados dessa investigação podem prover dados ou características como medidas indicadoras de esforços cognitivos associados a perfis diferenciados, no caso das áreas de conhecimento, que envolvam processos de raciocínio espacial. O entendimento sobre o esforço manifestado pelo aluno durante o experimento foi interpretado como uma possível medida de um dos itens relacionados ao perfil cognitivo, à luz das Ciências Cognitivas (GARDNER, 1994, 2001, STERNBERG, 2000, PINKER, 1998).

Palavras-chave: Ciências Cognitivas. Neuroeducação. Eletroencefalografia. Inteligência Espacial.

Referência:

CHIARAMONTE, Marilda Spindola. Habilidade Cognitiva Espacial: uma medida com eletroencefalografia. Orientador: Milton Antônio Zaro. Coorientador: Maria Isabel Timm. Tese (Doutorado) - Programa de Pós-Graduação em Informática na Educação, CINTED/UFRGS, 2010, Porto Alegre, BR-RS. 